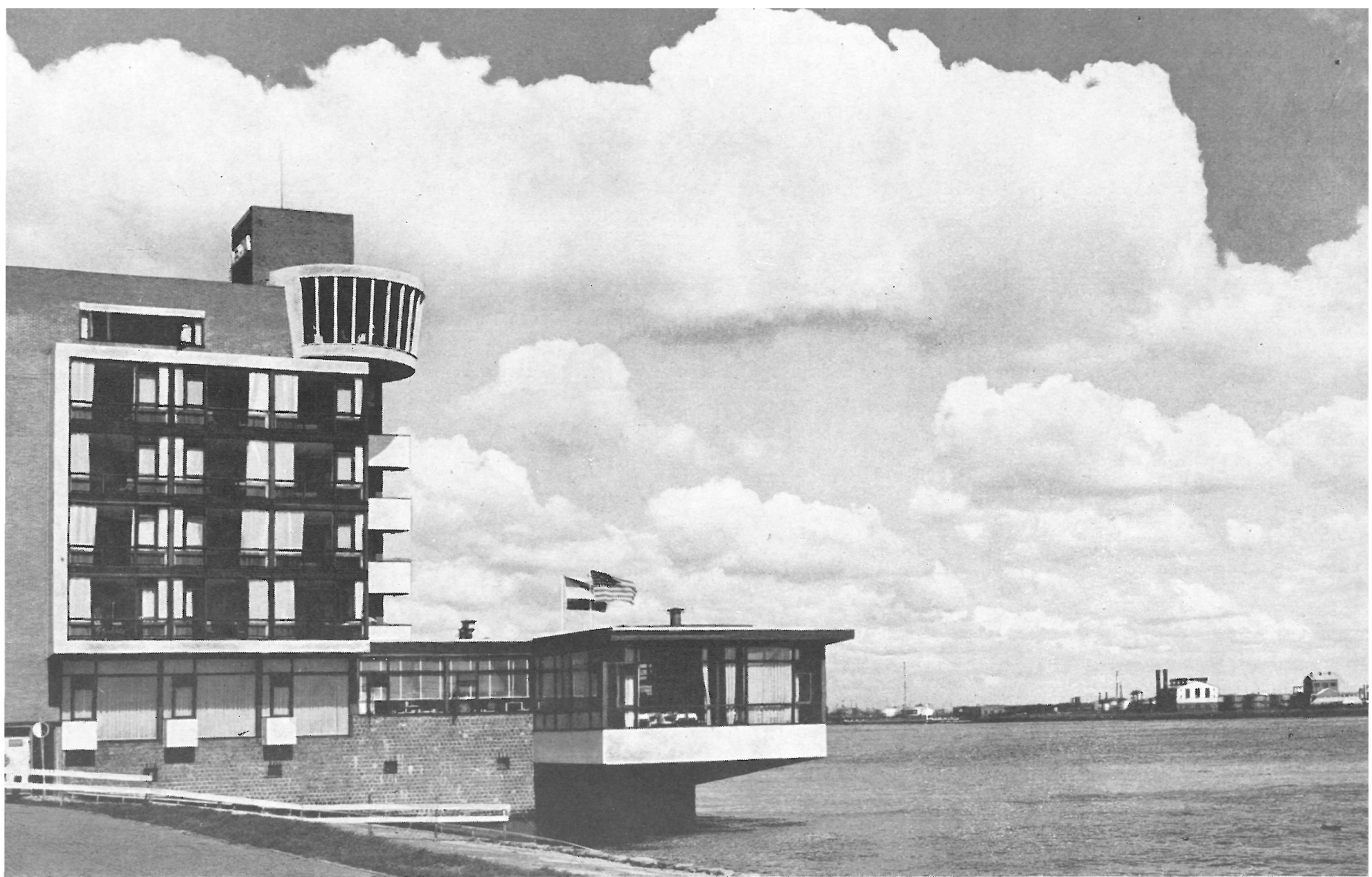

\title{
hotel Delta
}

Ir. J. W. C. BOKS, arquitecto

$147 \cdot 11$

Vlaardingen,

el tercer puerto de los Países Bajos en la Meuse, cerca de Rotterdam, al oeste de esta ciudad, es una ciudad que se desarrolla rápidamente. Este crecimiento fué debido, principalmente, al desarrollo industrial de la región.

Vlaardingen no posee ninguna hotelería importante $\mathrm{y}$, por lo tanto, los turistas tomaban alojamiento en las ciudades vecinas. Sobre la iniciativa del Ayuntamiento se empezaron estudios sobre la creación de un hotel de concepto original, sobre el boulevard de la Meuse.

El edificio, realizado por Ir. J. W. C. Boks, arquitecto de Rotterdam, comprende 48 habitaciones, una sala de reunión, dos restaurantes, una cafetería y un bar. Con fin de permitir a los huéspedes gozar del espectáculo animado de la navegación sobre la Meuse, la cafetería y la sala de reunión dan sobre el río, en construcción voladiza.

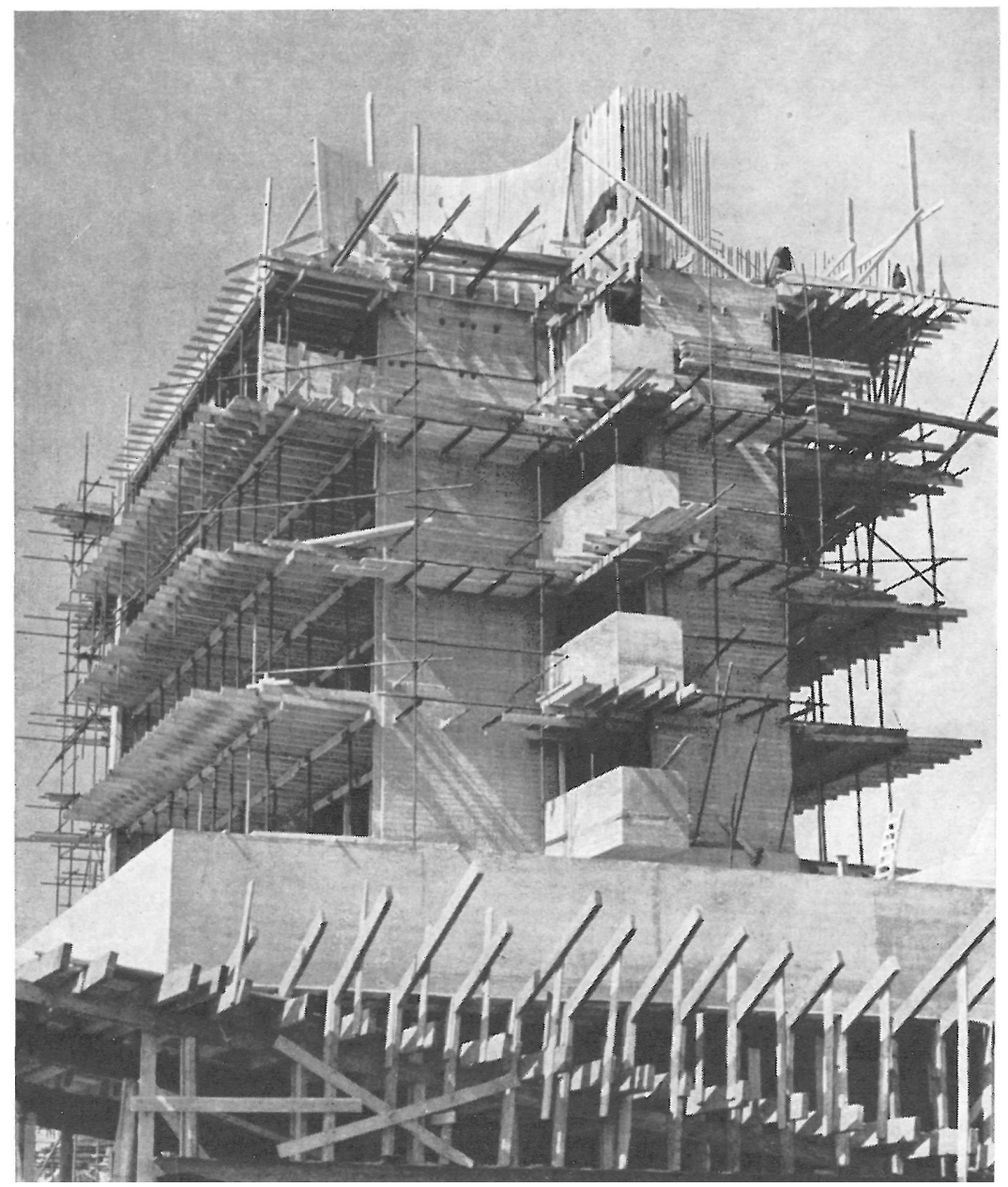




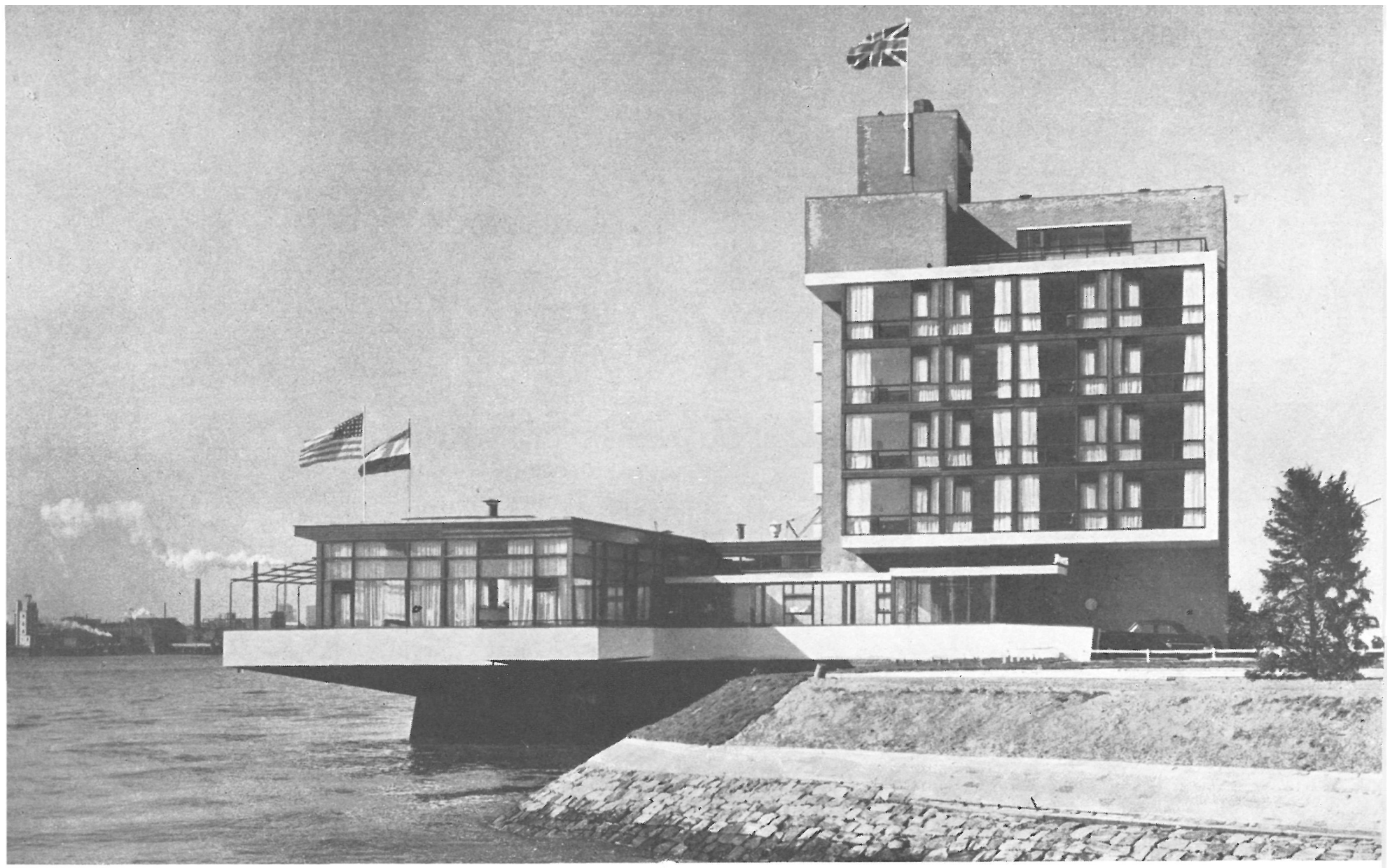

\section{planta de habitaciones}

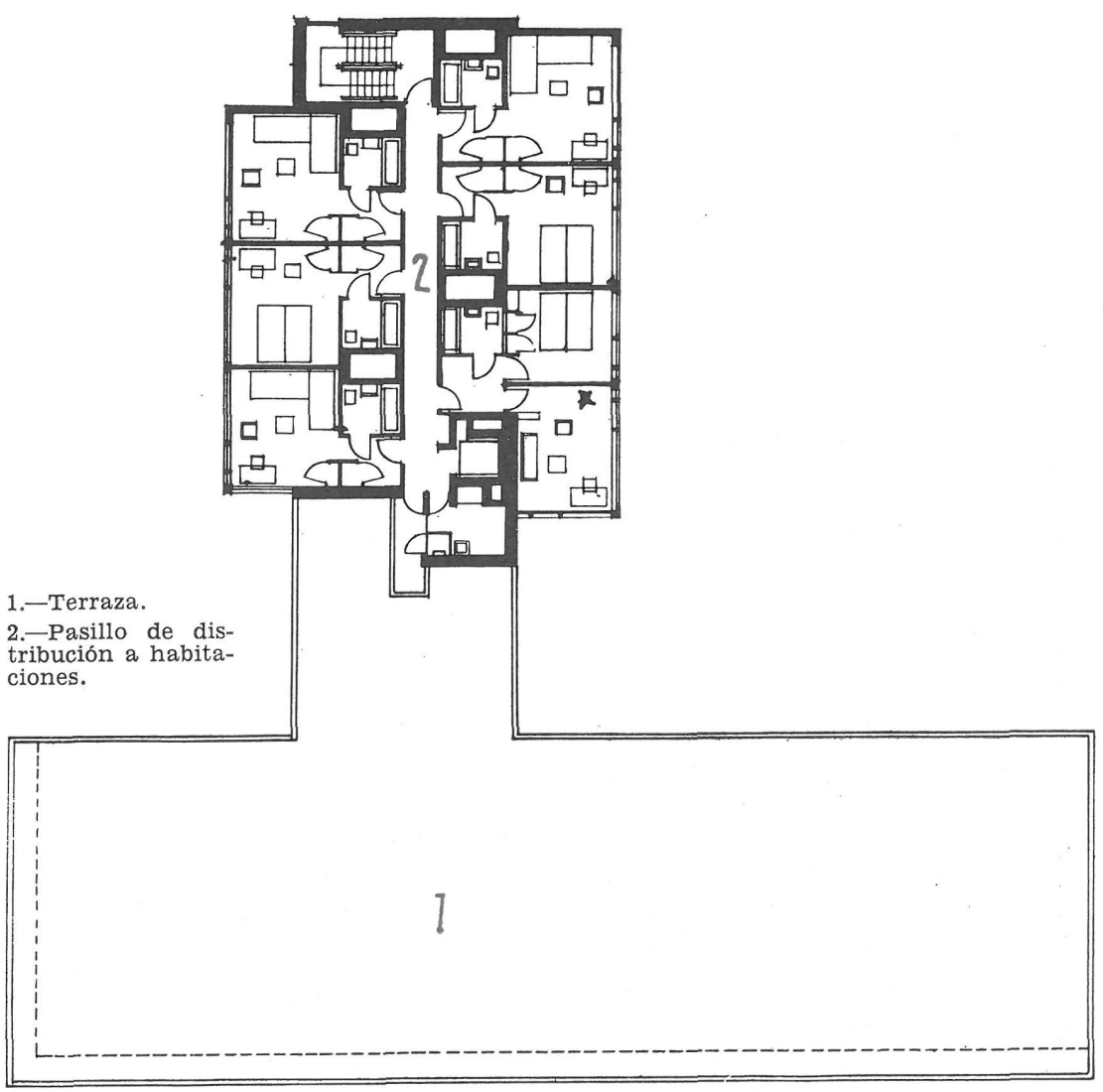

Las habitaciones están distribuídas en cuatro plantas y desde ellas se goza de una vista muy bonita sobre el río. Las habitaciones son de dos camas y cada una tiene su propio cuarto de baño. Los dos restaurantes se han instalado en el último piso. Uno, de forma circular, circundado enteramente con vidrieras, y llamado "el nido de pájaro», ofrece a los huéspedes una vista especialmente amplia. Por la noche,

la iluminación de las fábricas de petróleo que, situadas en la otra orilla, añaden un encanto particular a este restaurante panorámico.

Entre los dos restaurantes se encuentra un pequeño bar que se puede ensanchar por medio de divisiones móviles.

Una pasarela cubierta y enteramente vidriada relaciona la cafetería encima del agua con el hall de entrada del hotel, dando, de esta manera,

un acento de carácter marítimo al conjunto.

La construcción del hotel, empezada en otoño del año 1953, exigía la instalación de un dique en el río, en la protección del cual se realizaron los trabajos de fundación.

El edificio tiene estructura de hormigón armado. Los muros exteriores están revestidos con ladrillo rojo. Los cercos de puertas y ventanas son de madera de nogal. Todos los cuartos a los cuales el público tiene acceso están ventilados artificialmente.

Gracias a la iniciativa del Ayuntamiento, Vlaardingen cuenta hoy con un hotel cuyo aspecto exterior y confort interior atrae a muchos viajeros. 


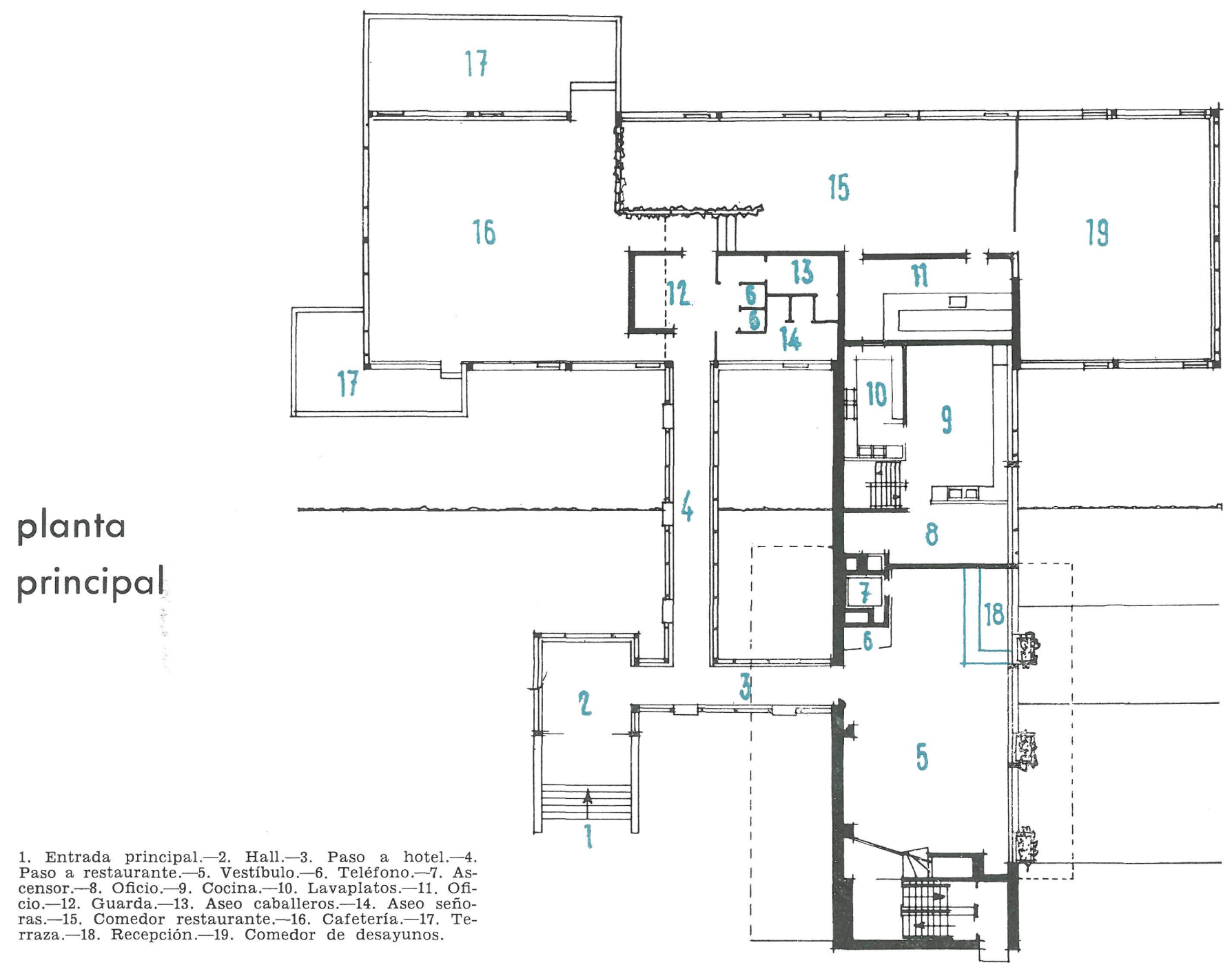

1. Entrada principal.-2. Hall.-3. Paso a hotel.-4. censor cio-12 Guarda-13. Aseo caballeros-14. Aseo seño-15. Comedor restaurante-16 Cafetería - 17. T rraza.-18. Recepción-19. Comedor de desayunos.

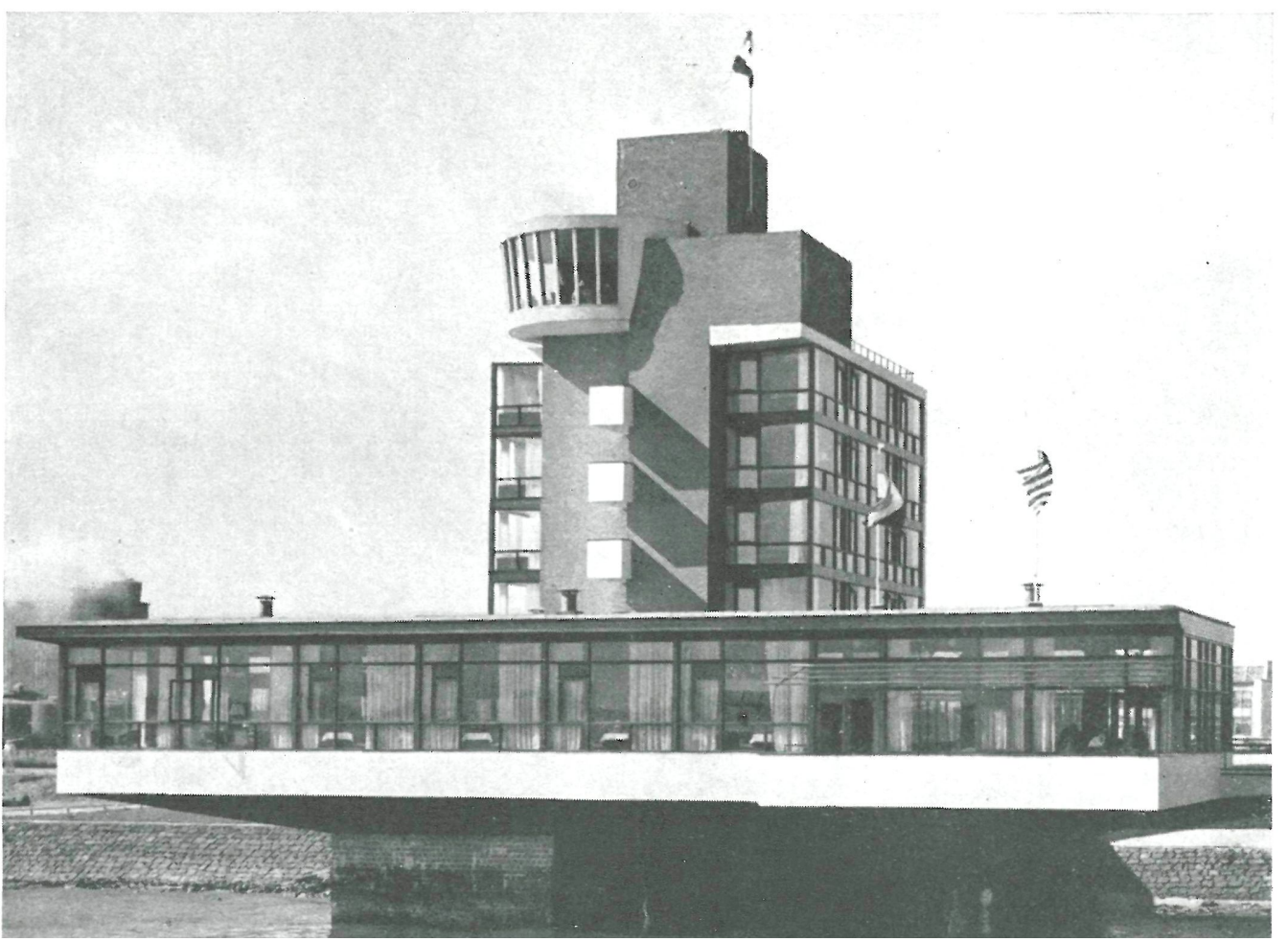



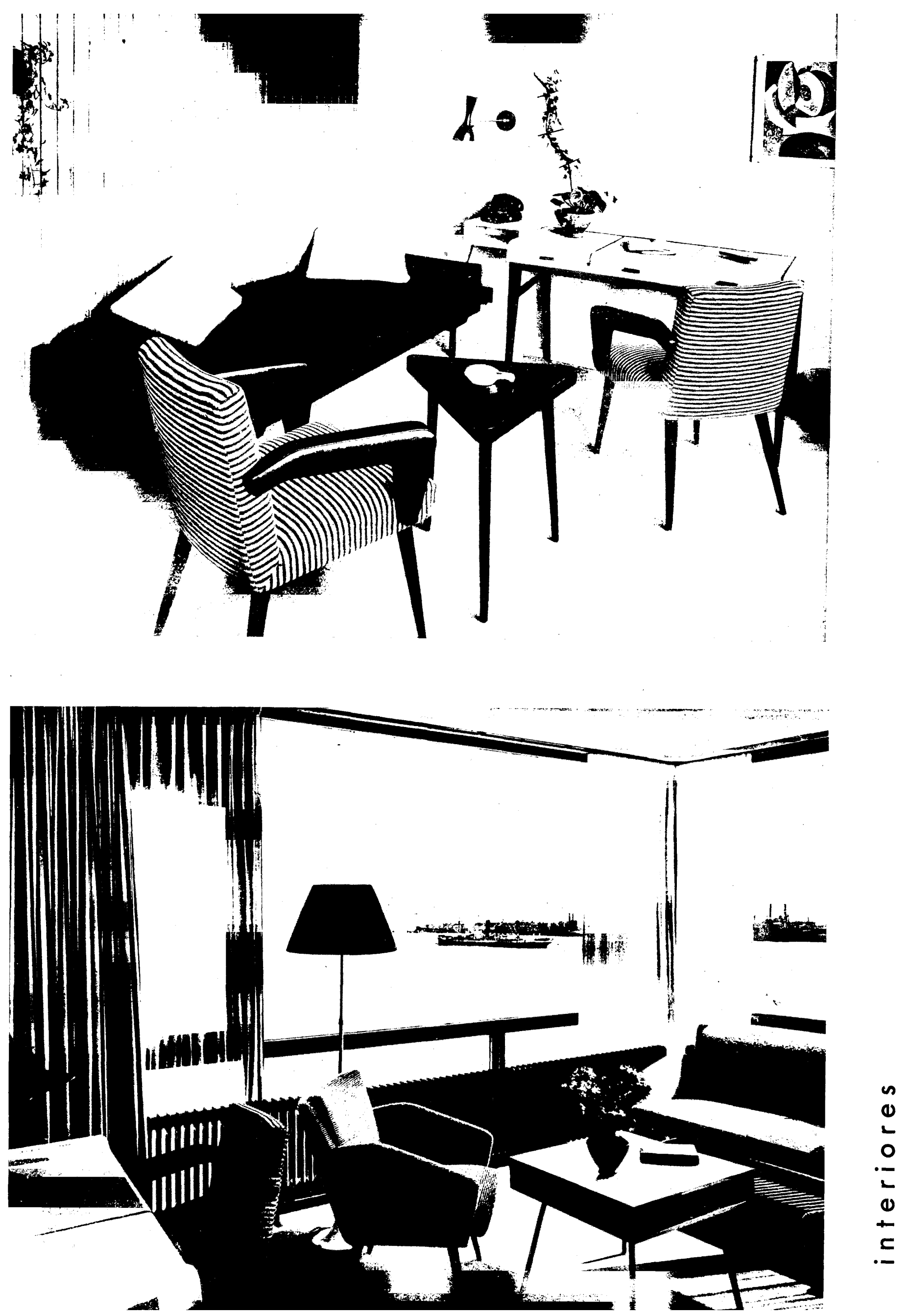